\title{
REFLEXIONES (Y UNA BREVE TRAVESIA LITERARIA) POR LOS DESIERTOS DE LA FRONTERA NORTE DE CHILE Y MEXICO
}

\author{
Gilda Waldman Mitnick ${ }^{9}$
}

RESUMEN: este artículo reflexiona en torno al desierto como metáfora de nuestra contemporaneidad, no sólo de la desolación sino también del tránsito, el cruce, el viaje y la migración. Al mismo tiempo, ofrece una cartografía de la actual narrativa sobre el desierto en países como Chile y México, en los cuales el desierto ocupa una vasta parte de su geografía, norteña y fronteriza, lindando con Perú y Bolivia en el primer caso y con Estados Unidos en el segundo. A partir de lo anterior, el texto reflexiona asimismo sobre las similitudes entre el desierto y la frontera y esboza algunas interpretaciones sobre por qué el desierto se ha convertido en un paisaje relevante en la actual narrativa de ambos países.

Palabras clave: desierto, frontera, literatura, Chile, México.

ABSTRACT: this text reflects upon the desert as a metaphor of contemporaneity; a metaphor about desolation, about transiting, crossing, travelling and migrating. Additionally, the text is also a cartography of the current wave of Chilean and Mexican narrative around the desert. Both countries have vast portions of their northern and borderline geography occupied by deserts (Peru and Bolivia in the former, United States in the latter). The text also reflects upon the similarities amongst desert and border, while it also draws some interpretations around the reasons why the desert has become such a relevant subject in both countries' narrative. Keywords: desert, border, literature, Chile, México.

En la enorme extensión geográfica que se extiende entre los confines del rio Bravo y la Patagonia están contenidos literariamente los

9 Doctora en Sociologia, Profesora de la Facultad de Ciencias Politicas y Sociales Universidad Nacional Autónoma de México. 


\section{0 | Gilda Waldman Mitnick}

más diversos paisajes ${ }^{10}$, incluyendo la ciudad cosmopolita e incluso algunos de sus barrios. A su vez, la geografía única del desierto es el territorio de las desventuras de La increible y triste historia de la cándida Eréndira y su abuela desalmada, (GARCÍA MÁRQUEZ, 1976), por ejemplo, y está presente en una vasta literatura argentina que construyó la geografía imaginaria de la nación como un gigantesco espacio vacío que se podia poblar (VIÑAS, 1983). Y, ciertamente, el desierto está presente en la literatura de países como Chile y México, en los cuales ocupa una vasta parte de su geografía, norteña y fronteriza, lindando con Perú y Bolivia en el primer caso y con Estados Unidos en el segundo. Así, por ejemplo, en el caso chileno, el desierto de Atacama, conocido como "el lugar más seco del mundo", ya fue descrito por los cronistas del siglo XVI "como reino de la sequedad y de la muerte" (OSTRIA, 2014, p.39) y, a pesar del aislamiento geográfico y de una identidad nacional construida simbólicamente sobre la vinculación con la agricultura y el campesinado del centro del país (BENGOA, 2009), el desierto ha sido una importante fuente de inspiración literaria. En poesía, por ejemplo, Gabriela Mistral ${ }^{11}$ lo describe como "costra terrestre despojada de toda gracia vegetal y de toda ternura de agua/ Su color es de un pardo blanquecino y desabrido cuando no es una reverberación de sol/. Su aire se reseca tanto que rompe la roca o el caliche en cascajos." (SCARPA, 1978, p.377). A su vez, Pablo Neruda, quien fuera senador por las regiones nortinas de Tarapacá y Antofagasta, escribía en sus memorias: "En pocos sitios del mundo la vida es tan dura y al par tan desprovista de todo halago para vivirla. Cuesta indecibles sacrificios transportar el agua, conservar una planta que dé la flor más humilde, criar un perro, un conejo, un cerdo." (1999, p. 191). De igual modo, el desierto de la pampa nortina, en el que se desarrolló la industria del salitre desde fines del siglo XIX hasta 1930, fue el espacio geográfico en el que se desarrolló la cuentística de Baldomero Lillo, referida a las inhumanas condiciones de la vida minera en las salitreras del norte del pais a principios del siglo $\mathrm{XX}$ (LILLO, 1907, p.1943). Asimismo, también la novela realista y de contenido político, ubicada el paisaje infernal de las oficinas salitreras ${ }^{12}$, recreó las precarias condiciones de vida de los trabajadores del salitre en

\footnotetext{
${ }^{10}$ Por ejemplo, la selva, la pampa, los bosques lluviosos, la sabana venezolana, los paisajes rurales mexicanos y los altiplanos andinos.

${ }^{11}$ Escritora Chilena nacida en el valle de Elqui, una zona estrecha y fértil al sur del desierto de Atacama.

${ }^{12}$ Adonde habian migrado hombres y mujeres en busca de oportunidades de progreso y que fue el motor de las transformaciones sociales y politicas que marcaron al pais durante el siglo $\mathrm{XX}$ a través del crecimiento del comercio, la industria y el aparato estatal.
} 
Reflexiones (y una breve travesia literaria) por los desiertos de la frontera norte de Chile y Mexico | 51

esta zona, misma que también fue escenario de guerras, de la formación del proletariado y la conciencia obrera en Chile, y de conflictos sociales que llevaron a masacres como la de Santa María de Iquique en 1907 (TEITELBOIM, 1952; SABELLA, 1966). Dicha creación literaria enunciaba al desierto no sólo como un espacio de extraordinaria dureza geográfica, sino también como un "escenario de muertes épicas y trágicas." (OSTRIA, 2014, p.40).

A su vez, en la literatura mexicana, el desierto es el paisaje de fondo, por ejemplo, en los cuentos de Emma Dulajanoff (1959), referida a los indios mayos que viven en el desierto de Sonora. También lo es en los cuentos de Ramon Rubin AGRUPADOS EN SU LIBRO Cuando el Táguaro agoniza (1960) ubicados igualmente en el desierto de Sonora en la década de los cuarenta, así como en la novela del escritor chicano Miguel Méndez, El circo que se perdió en el desierto de Sonora (MÉNDEZ, 2002), que narra el hilarante (y trágico) deambular de los personajes de un circo en medio del calor alucinante del desierto hasta culminar en un extravío existencial que los lleva a la muerte.

Ciertamente, el desierto ha sido un espacio geográfico muy presente a lo largo de la historia y la cultura de Occidente. Cuna de las tres grandes religiones, espacio de peregrinación y refugio de eremitas, posee una larga tradición como lugar de iniciación, purificación o sanación en términos físicos y espirituales ${ }^{13} \mathrm{y}$ ha sido fértil fuente de inspiración para fotógrafos, cineastas y viajeros. La cultura popular también lo ha incorporado de manera importante en sus más variadas expresiones. Así, por ejemplo, el western está directamente asociado a una iconografía en la que la conquista del oeste se juega en medio de la hostilidad del terreno desértico. Por otra parte, la ciudad de Las Vegas fue construida en medio del desierto de Mojav. Indudablemente, el desierto ha sido también un gran tema literario. Siguiendo a Edmond Jabés, porque el desierto, con su escasez de agua y de sombra, es metáfora de un espacio en blanco, e incluso irreal, en el que la palabra se ofrece en su libre desnudez, permitiendo imaginar ficcionalmente mundos distintos. Paisaje carente de detalles, obliga a crearlos en la mente. En palabras de Jabés, el desierto es "el lugar verdadero de la palabra, donde ésta tiene carta de ciudadania en el silencio de las otras palabras." (JABÉS, 2001, p.83). La carencia existente en el desierto, más allá del desamparo que genera, es

\footnotetext{
${ }^{13}$ Presente, por ejemplo, en las ceremonias de curación de Maria Sabina en México, o en las enseñanzas de Don Juan, descritas por Carlos Castañeda.
} 


\section{2 | Gilda Waldman Mitnick}

condición positiva y vital para la escritura. La página en blanco recrea la sensación de silencio y vacío que se vive en él. En la neutralidad de su colorido, encierra el misterio de una geografía abierta a un juego fabuloso de la creación y del sueño. El desierto es el espacio privilegiado de la experiencia de la palabra. Paisaje carente de detalles, elusivo, inasible, imposible de poseer, obliga a crearlos en la mente. Por otra parte, como escribe Michael Ondaatje (1997, p.17), "el vacío de los desiertos siempre está rodeado por las historias perdidas".

Si el desierto ha sido un pasaje literario en la poesía y narrativa de la literatura chilena y mexicana durante la primera mitad del siglo XX, ha sido en las últimas décadas que, dentro de la diversidad de corrientes y temáticas que forman el entramado de ambas literaturas, el desierto como paisaje literario ha alcanzado un lugar de gran vitalidad, inserto en lo que Patricio Manns (2002) ha denominado la "literatura de los espacios abiertos", en la cual es sustancial la relación del hombre con la naturaleza como espacio no civilizado, no corruptor, no seguro, no ordinario, no conocido. Así, por ejemplo, en Chile, en el marco de la enorme cartografía de la literatura chilena actual ${ }^{14}$, y más allá de que el norte chileno pudo crear, un imaginario propio que marcó la cultura de esa región, resulta interesante destacar la recuperación del desierto de Atacama y sus pampas interminables como territorio imaginado en la obra de un escritor emblemático en esta línea, Hernán Rivera Letelier, quien ha desarrollado una vasta obra compuesta por una serie de novelas que tienen como escenario los pueblos mineros "del desierto más triste del mundo" (RIVERA LETELIER, 2000, p.7), "esa tierra de nadie" (RIVERA LETELIER, 1998, p.7), a los que llegaron miles de hombres y mujeres del centro y sur del país a trabajar en la industria del salitre, y quienes crearon una identidad y una cultura propia, la "pampina", indisolublemente ligada al desierto. En esta línea, desierto y salitre constituyeron "dos ejes esenciales imposibles de separar: El desierto es el hábitat del pampino" (GONZÁLEZ MIRANDA, 2002, p.31), separados del resto del país por la frontera del paisaje lunar, casi sobrenatural, del desierto y sus suelos áridos proclives al espejismo. Pero, al mismo tiempo, las novelas de Rivera Letelier, ubicadas en las oficinas y campamentos salitreros de "aquella

\footnotetext{
${ }^{14}$ Cartografia en la que convergen la novela histórica, el género negro, la ciencia ficción, el género testimonial, la autoficción y la autobiografia, el experimentalismo escritural, el regreso a los origenes genealógicos, el abordaje de lo periférico y marginal, entre otros temas(KOHUT Y MORALES, 2002; MORALES EBENER, 2011; AMARO, 2014; ARECO, 2015)
} 
Reflexiones (y una breve travesia literaria) por los desiertos de la frontera norte de Chile y Mexico | 53

grandiosidad sobrecogedora de la pampa" (RIVERA LETELIER, 1998, p. 142) es, al mismo tiempo, la historia de su abandono y despoblamiento, es decir, la conversión de sus habitantes en seres sin raíces ni pertenencia. Su obra literaria es la memoria de las oficinas salitreras convertidas hoy en ruinas fantasmagóricas, casi totalmente abandonadas en mitad de un desierto inclemente. En un tono nostálgico, pero también lúdico y casi hilarante, con una crítica social implícita desprovista, sin embargo, de los matices de denuncia que tuvo la literatura politica previa sobre la vida de las salitreras, pero teñido al mismo tiempo de melancolía y con un lenguaje popular que rescata la oralidad de los habitantes de los pueblos pampinos, los relatos de Rivera Letelier se ubican en los restos mudos de un mundo ya virtualmente desaparecido, en los que sólo queda el recuerdo del pasado glorioso nortino y un paisaje que es siempre el mismo: el desierto de Atacama con sus pozos de arena, zanjas, polvo, viento brutal, ausencia de maleza, piedras ardientes, etc.

En un registro distinto, la geografía literaria del desierto asume una connotación eminentemente política -que la ubica en el marco de lo que ha sido en Chile la novela de la dictadura y la transición democrática - en la novela El desierto, de Carlos Franz (2005), ubicada en un pequeño poblado perdido del desierto de Atacama, Pampa Hundida. En aquel poblado desértico, donde funcionaron anteriormente las antiguas salitreras, se instaló durante la dictadura militar (1973-1990) un campamento militar y un campo de concentración de prisioneros políticos, más tarde fusilados o desaparecidos, y cuyos huesos quedaron sumergidos en el cementerio desértico del norte chileno. Hasta alli regresa, en 1993, Laura, una ex jueza durante los primeros años de la dictadura, para retomar su antiguo trabajo, y esencialmente para responder la pregunta de su hija: “Dónde estabas tú, mamá, cuando todas esas cosas horribles ocurrieron en tu ciudad?"(FRANZ, 2005, p.12). Si el tema de la novela es la responsabilidad colectiva ante el quehacer criminal de la dictadura, sea por indiferencia o por miedo, el paisaje desértico, "una catarata de aire hirviente manando del cielo quemado por el reflejo de los salares" (2005, p.5), es el espacio de la intemporalidad total, donde Laura podrá realizar la catarsis de su memoria para enfrentar los secretos de un pasado trágico que se ha negado a recordar: su relación erótica -cercana al síndrome de Estocolmo- con el mayor Cáceres, su verdugo y torturador. El desierto es para Laura un espacio de redención física y espiritual para sobreponerse a la violencia del drama político que le tocó vivir. 


\section{4 | Gilda Waldman Mitnick}

Pero la violencia del desierto puede asumir muchas formas, convirtiéndose también en una importante fuente de inspiración artística para un escritor joven como Diego Zuñiga, por ejemplo, quien en sus dos novelas, Camanchaca (2012) y Racimo (2014), visualiza el desierto como metáfora de la violencia (oculta e invisibilizada) de la historia chilena. En la primera -a través de un relato fragmentado y contenido sobre el viaje de un adolescente llevado por su padre desde Santiago hacia Tacna para comprar ropa e ir al dentista - el desierto, "azul, como si lo cubriera un manto" (ZÚÑIGA, 2012, p.29), es un paisaje no sólo vacío e inhabitado, silencioso e inamovible, sino también desolado e indescifrable en el que se esconden secretos familiares inconfesables. En la segunda - un relato policial narrado en clave de crónica periodística - Zúñiga devela el lado más oscuro del desierto de Atacama, agreste y peligroso, que fuera en la segunda mitad de la década de los años cuarenta una prisión para opositores politicos (TEITELBOIM, 2002), como también lo fue en la reciente dictadura militar chilena. Pero también en ese desierto, en su inmensidad y silencio sin límites, se puede asesinar y ocultar los cadáveres de las jóvenes asesinadas en Alto Hospicio, una ciudad de "cinco casas en medio del desierto, al lado de un par de basureros clandestinos" (ZÚÑIGA, 2012 , p. 31) surgida en la década de los ochenta en medio de la tierra calcinada del desierto.

En el caso mexicano, también el desierto se ha convertido en un paisaje literario relevante, en el marco de una vasta creación literaria de notable riqueza en sus propuestas literarias y narrativas, que contrasta con la relevancia que a lo largo del siglo XX tuvo la literatura del centro y sur del país. Es así que en el vasto y movedizo territorio de la frontera mexicana-norteamericana se ha hecho presente a lo largo de las últimas décadas un caudal de escritores nacidos o radicados en el norte del pais ${ }^{15}$, que han dado voz a una realidad heterogénea, diversa, plural y, ciertamente, conflictiva: la de una región con características propias, en el que

hay un devenir muy distinto al que registra la historia del resto del pais: una manera de pensar, de actuar, de sentir y de hablar derivadas de ese mismo devenir y de la lucha constante contra el medio y con la cultura de los gringos,

15 Entre los que destacan, por ejemplo, autores como Eduardo Antonio Parra, Luis Humberto Crosthwaite, David Toscana, Federico Campbell, Rosina Conde, Gabriel Trujillo Muñoz, Julian Herbert, Yuri Herrera, entre otros. 
Reflexiones (y una breve travesia literaria) por los desiertos de la frontera norte de Chile y Mexico | 55

extraña y absorbente. $Y$ esta particularidad del "ser norteño" es la materia prima de la narrativa de sus escritores (PARRA, 2003, p. 40).

Si bien "la literatura del norte" encuentra sus antecedentes en escritores de la primera mitad del siglo XX, de la talla de Martín Luis Guzmán, Alfonso Reyes, Julio Torri, José Revueltas, Inés Arredondo, entre otros (PARRA, 2015), la realidad contemporánea signada por procesos como la rápida urbanización, la apertura económica, la inversión norteamericana que se ha traducido en la proliferación de la maquila, la llegada de enormes flujos de población que intentan cruzar a Estados Unidos, y ciertamente, la criminalidad, el narcotráfico, la explotación laboral y la trata de personas, ha dado paso no sólo a expresiones literarias de una amplia diversidad temática sino también a "diferencias de lenguaje, de pensamiento, de idiosincrasia, de clima, de paisaje y de atmósfera" (PARRA, 2015 , p.9). Es en el entorno de este movimiento literario en la frontera norte de México que emerge con gran fuerza el espacio físico del desierto, donde prima la aridez y la sequedad y en el que se juega una feroz lucha por la vida y por la sobrevivencia. Como escribe Gabriel Trujillo en su ensayo Visiones y espejismos: "Lo que soy está hecho de desierto, la más profunda (realidad) de todas, la de nuestro medio natural, que ha moldeado nuestra historia y ha definido nuestra idiosincrasia como individuos y como sociedad." (Citado por CARRERA, 2009).

El desierto alcanza en la obra de autores como Jesús Gardea, Daniel Sada y Ricardo Elizondo, entre otros, un lugar relevante y definitivo en la literatura del norte, configurando mundos imaginarios y espacios simbólicos. Tal es el caso de Perdomo ${ }^{16}$, en la novela Narcedalia Piedrotas (2002), de Ricardo Elizondo. Asimismo, en la obra cuentística de Jesús Gardea (1999), el desierto es el protagonista de los relatos, modelando a sus personajes e imponiéndose a ellos. "Yo creo - dijo Blas Candumo a Angel Nacianceno- que es tanto calor lo que nos transtorna. En la tierra de usted, la influencia del astro es perniciosa, es desmesurada. Usted pensará de mí que me he vuelto loco." (GARDEA, 1999, p.33). ¿Cómo podría no influir la geografía indómita que envuelve el paisaje desértico en los personajes de Gardea: contenidos, parcos, austeros, de rostros

\footnotetext{
16 Espacio en que transcurre la novela Narcedalia Piedrotas (2002), de Ricardo Elizondo, un pequeño caserio casi abandonado, en pleno desierto castigado por el sol, lleno de arenales y pedregoso, falto de agua y abundante en viento y polvo
} 


\section{6 | Gilda Waldman Mitnick}

oscuros y desolados, habitantes de silencio y la soledad de los paisajes inconmensurables, y que llevan el desierto en su historia y en la sangre?

No es casual que el desierto aparezca en la actualidad como paisaje literario relevante en un momento en que América latina re-escribe su historia, replantea sus orígenes y busca un proyecto de futuro. Si bien no puede dejar de reconocerse que América Latina pudo ser pensada y registrada literariamente desde la selva, la sabana, los bosques o las ciudades, la cartografía de sus diversos territorios no ha podido escapar a una historia leída recurrentemente como la promesa del proyecto moderno a realizarse dentro de los límites físicos geográficos jurídicos y políticos de un territorio. Hoy sin embargo, a la luz de las fracturas y contradicciones de un discurso histórico insuficiente para legitimar un proyecto de nación y de identidad nacional sustentados sobre los principios de unidad política y homogeneidad, nuevas geografías disimiles -entre ellas el desierto- comienzan a aparecer en la literatura obligando a volver el rostro a los relieves, quiebres y discontinuidades del paisaje nacional. En el actual escenario literario de América Latina, la preeminencia alcanzada por la literatura que privilegia al desierto como paisaje geográfico no sólo evidencia que, más allá del tradicional centralismo cultural y político que convertía en periferia todo lo que tocaba, ella puede en última instancia recuperar la presencia ineludible de lo que aparecía reprimido, subordinado y olvidado en el imaginario simbólico nacional: la compleja diversidad de paisajes memorias, lenguajes e historia. Recuperar literariamente al desierto implica ubicarse a contracorriente de un imaginario cultural centrado en los conceptos de Estado-nación, territorio e identidad nacional, conceptos minados por la globalización económica y cultural. Incorporar literariamente al desierto, un espacio geográfico que perturba y descentra las naciones de nación e identidad, supone incorporar geografías que históricamente habían quedado al margen de la cartografía simbólica nacional. La literatura centrada alrededor del desierto advierte que el sentido del centro está desplazado (¿cuál sería el centro en medio de la tierra calcinada del desierto?), y que resulta imperativo volver los ojos a un paisaje periférico que se inserta en un nuevo horizonte de significación cultural que redefine los sentidos de pertenencia en un entorno de desterritorialización, exclusión y fractura social (CHAMBERS, 1994; HOPENHAYN Y SOJO, 2011). Asimismo, recuperar literariamente al desierto supone buscar su particularidad regional, distinta por su diversidad y lejanía con el resto del país y su pasado común. 
Reflexiones (y una breve travesia literaria) por los desiertos de la frontera norte de Chile y Mexico | 57

El espacio desértico adquiere, así, una vida propia en esta nueva relevancia de lo regional. Ello coincide con una interesante vertiente temática en la más reciente narrativa latinoamericana referida al retorno a las provincias olvidadas y a los pueblos de los confines. Este repliegue a espacios territoriales locales pone al paisaje en el centro de la narración, convirtiéndolo en personaje central del relato. Así, por ejemplo, la escritora argentina Selva Almada ubica sus novelas El viento que arrasa (2012) y Ladrilleros (2013) en pequeñas localidades del norte de ese país en medio de horizontes descuidados, un sol abrasador, calores agobiantes y húmedos, escasa vegetación, un tiempo detenido y un escenario social no sólo patriarcal y abusivo en el que se esconden resentimientos ancestrales, sino también una violencia contenida que explota en ajustes de cuentas y sangre. A su vez, las novelas de Hernán Roncino, La descomposición (2007), Glaxo (2009) y Lumbre (2013) se desenvuelven en un pequeño pueblo cercano a Buenos Aires, del cual solo quedan ruinas y fábricas cerradas, donde ya no llegan los trenes, y en el cual los personajes - tan desolados como el paisaje - reflexionan sobre la memoria, la política, el paso del tiempo.

Por otra parte, si la literatura del desierto construye un nuevo imaginario cultural que busca rescatar las huellas perdidas, los rostros y voces que perturban una historia única y que han quedado fuera del relato nacional, ello es especialmente relevante en países en los que ha prevalecido la tendencia a la centralización excesiva, acompañada por un presidencialismo fuerte, como es el caso de Chile y México. Ninguno de estos dos países -donde la formación y consolidación del Estado se realizó desde el centro a la periferia- se ha pensado desde sus zonas limítrofes, norteñas y desérticas. Más aún: en ambos casos, ha existido una relación conflictiva con sus zonas desérticas. En el primer caso, y ligado al aislamiento geográfico, si bien Chile ha dependido económicamente de los minerales existentes en el desierto, introduciéndose en la modernidad a través de la explotación del salitre primero, y del cobre después, y de que fue alli donde surgieron las primeras y más importantes formas de organización obrera, la historia del norte y del desierto ha sido desdibujada y olvidada, incluyendo ciertamente en ese olvido a los trabajadores de las minas y a su historia de explotación y masacres. Aunque Chile se ha esforzado históricamente por aparecer ante el resto de los países de la región como un modelo singular y paradigmático, tras su (supuesta) "excepcionalidad" se ocultaba, entre otras cosas, la violencia soterrada en la vida politica y social del país (JOSELYN-HOLT, 2005), 


\section{8 | Gilda Waldman Mitnick}

expresada, por ejemplo, en la represión en contra de los incipientes movimientos de reivindicación social en la zona salitrera y portuaria del norte del país (Valparaíso 1903; Santiago, 1905; Antofagasta 1906; Santa Maria de Iquique, 1907). De igual modo, la proletarización de vastos sectores populares y el desarraigo de una masa poblacional que migraba del campo a la ciudad en el marco de una paulatina industrialización dio origen a numerosos estallidos sociales, mismos que fueron severamente reprimidos a través de métodos a los que no fueron ajenos un sistema carcelario denigrante y la utilización de la tortura, una práctica de larga tradición en el país, en especial en relación a investigaciones por delitos comunes (VIDAL, 2000) y en el que los espacios nortinos fueron en varios momentos del siglo XX, espacios de reclusión y cárcel, marginados en la memoria nacional. La cultura política centralista chilena, al privilegiar al valle central, dejó en la marginalidad a las regiones fronterizas del norte. El desierto nortino es, así, el contrapunto al centro y al sur del país. Es un espacio asociado en el imaginario nacional a la industria salitrera, a la emergencia del proletariado y a una larga historia de masacres, muy ajeno a la vegetación de la zona central, que posibilita la actividad agropecuaria, o a la naturaleza lluviosa del sur.

Por otra parte, el norte mexicano ha sido también una zona que ha tenido una compleja relación con el resto del país, no sólo por la presencia de tribus apaches que atacaron esa zona del país durante los siglo XVIII y XIX hasta el comienzo de la Revolución Mexicana comenzada precisamente en el norte - sino esencialmente porque en 1848, con el desplazamiento hacia el sur de lo que era la frontera mexicano-norteamericana quedó en ese país la percepción de la frontera como "ruptura, mutilación territorial, herida abierta o fractura" (VALENZUELA, 2003, p.33). En esta línea, a la herida causada por la anexión de más de la mitad del territorio mexicana a Estados Unidos, cabe agregar que la geografía lejana y árida del desierto, el nomadismo de las poblaciones indigenas norteñas y su falta de organización estatal, el miedo a esa población indígena, -tan distinta a los del altiplano- la debilidad demográfica, etc., resultaron ser completamente lejanas a los mexicanos del centro y del sur. La lejanía del territorio y del desierto como parte de una identidad nacional cuyo núcleo estaba en el centro, así como la ajenidad al pasado indígena azteca -sinónimo de lo mexicanoque marcó la historia centralista del país, configuraron en el imaginario nacional al norte y al desierto como un espacio ajeno a la "civilización" (RAJCHENBERG Y HÉAU-LAMBERT, 2012), en un claro distanciamiento de la frontera con respecto al centro político del país, y 
Reflexiones (y una breve travesia literaria) por los desiertos de la frontera norte de Chile y Mexico | 59

en una suerte de extrañamiento geográfico y cultural. El norte del país y el desierto quedaron desvinculados del "territorio patrio" y de la nación, ajenos a los "geosímbolos dominantes de la patria, como referentes de la identidad nacional, (que fueron) siempre los volcanes y las pirámides aztecas, pero nunca los elementos de la geografía de los desiertos". (GIMÉNEZ Y HÉAU. LAMBERT, 2007)

Pero por otra parte, el desierto como paisaje geográfico -más allá de que casi la mitad de la superficie terrestre está en proceso de desertificación- está cargado de significaciones culturales, y hoy se ha convertido también en un tema importante en las Ciencias Sociales. Por una parte, porque constituye una metáfora con la que la posmodernidad se refiere a la desolación interior (LIPOVTEZKY, 1986), y también porque en su fluidez, forma parte de la construcción de un nuevo paisaje teórico cultural. Es así que en las últimas décadas la figura del desierto se inscribe en uno de los itinerarios más debatidos de la reflexión contemporánea: el viaje como metáfora para repensar la cultura de nuestros tiempos, el desarraigo como destino del mundo, el movimiento como desplazamiento entre una morada inicial y la promesa ¿imposible? de una vuelta a casa (CHAMBERS, 1994). El desierto se ha convertido, así, en metáfora del nomadismo en el marco de las migraciones y desplazamientos que, por razones politicas y/o económicas, caracterizan al paisaje contemporáneo poblado de figuras en tránsito o desplazadas, y que problematizan las nociones de pertenencia y arraigo en una época de incertidumbre, fragilidad, inseguridad, fluidez, volatilidad y precariedad (BAUMAN, 2003) en la que el saber, el poder, el trabajo, el ejército, la familia o los partidos ya no son principios absolutos en el nuevo mapa social, político, económico y cultural de nuestro tiempo (LIPOVETZKY, 1986). En otras palabras, en lo que Edward Said ha llamado "una condición generalizada de desarraigo", en la que "hace falta muy poco para que el arraigado se vea arrancado de sus raices y para que el feliz y sosegado pierda su lugar al sol" (WIESEL, 1991, p.19), recuperar el desierto es repensar la cultura en términos de viaje, abierto, incompleto.

Geografía antigua y poderosa, la infinitud de su arena es fluida e infinita. El desierto es, así, un paisaje mudable, variable, provisional, arrastrado por el viento y no sujeto por piedras. El desierto apela al nomadismo, a un lugar de tránsito, a la ausencia de seguridad, a la morada como un hábitat móvil, es decir, 
como una forma de vivir el tiempo y el espacio no como si fueran estructuras fijas y cerradas sino como fuentes que incitan a una apertura crítica cuya cuestionadora presencia cuestiona las certezas de la identidad, del hogar y de la pertenencia (CHAMBERS, 1994, p.18).

La metáfora del desierto entraña una fabulación en la que no existe identidad fija ni destino final. La naturaleza fluida del desierto nunca coincide del todo con la nación ni con el Estado. Es el espacio sin limites donde todo es posible, metáfora del carácter dislocado del sujeto de fin de siglo y de su forma de estar en el mundo: nómade, foráneo, descentrado, desplazado y trágicamente desolado. Carente de centro, el viaje en el desierto es una travesía discontinua, abierta e incompleta. En el desierto, todo arraigo se vuelve volátil e inestable. No hay en el desierto "un" solo lugar, sino una multiplicidad de paisajes mudables, leves, transitorios.

El desierto está marcado por el horizonte de la alteridad. Al igual que la frontera, divide lo que está dentro y lo que se encuentra fuera. Ambas separan al Nosotros del Ellos. Al igual que la frontera que divide, identifica, incluye y excluye, la tierra incógnita del desierto sugiere lo desconocido, lo prohibido, lo proscrito, lo otro, extraño y ajeno. Al igual que la frontera, tensa y peligrosa, puede ser herida cuyo dolor sirve para reafirmar la identidad, el espacio desértico sin vegetación ni habitantes puede ser una fortaleza, demarcada del resto del país al que pertenece.

Pero si bien los mapas fronterizos pueden subrayar la exclusión, las fronteras se pueden transgredir, cruzar, traspasar ¿Quién no las ha cruzado alguna vez? Por naturaleza, la frontera es un espacio abierto y de aperturas, aunque esté delimitado por alambradas, muros o ríos. De igual modo, el desierto -un lugar desnudo, sin caminos prefijados- es un espacio de cruces. Así, por ejemplo, por el desierto de Atacama han cruzado históricamente incas, españoles, ingleses, y sobre todo miles de trabajadores campesinos del centro y sur de Chile decididos a poblar la pampa en más de trescientas oficinas salitreras. Por el desierto literario de Hernán Rivera Letelier han cruzado prostitutas insólitas, adolescentes que luchan por la sobrevivencia, poetas que escriben cantatas, viejos sobrevivientes de antiguas masacres, quirománticas de ojos misteriosos, una madre en busca de su hijo, un acordeonista que regresa a la pampa buscando en cada mujer a la mujer amada y perdida, o personajes excéntricos, marginales y un tanto hilarantes. Pero el desierto de Atacama se ha convertido hoy en una zona de cruce para inmigrantes ilegales, una 
Reflexiones (y una breve travesia literaria) por los desiertos de la frontera norte de Chile y Mexico | 61

zona fronteriza entre la vida y la muerte. Si bien es cierto que la frontera norte de Chile que conecta con Perú y Bolivia ha sido históricamente una zona de cruces económicos, culturales y de personas, el intenso flujo migratorio que existe desde hace algunos años hacia Chile (en busca del "sueño chileno") y la severidad de las políticas migratorias de este país provenientes todavía del período dictatorial y basadas en la noción de "seguridad"- han convertido en la actualidad a dicha región en una zona de confluencia de ecuatorianos, colombianos y dominicanos que, impedidos en muchos casos de ingresar de manera legal, se vuelven presa fácil de mafias y grupos organizados que les ofrecen documentos falsos y los conducen por diferentes cruces clandestinos, o por el desierto de Atacama (SALINAS, 2015; FREIXAS Y LABBÉ, 2016), corriendo el riesgo de ser abandonados, ser encontrados por la policía y deportados, ser víctima de minas sembrada décadas atrás, o pasar a formar parte del extendido comercio de trata de personas.

Por su parte, la frontera entre México y Estados Unidos es la que tiene el mayor número de cruces legales e ilegales en el mundo. Es el espacio donde se encuentran la realidad de la globalización y la del subdesarrollo y, al tiempo que divide tangencialmente universos que parecen no tocarse ni cruzarse, las voces se mezclan y los espacios se entrelazan para redefinir, mutuamente, las señas de identidad. Si para la imaginación norteamericana la frontera con México fue durante décadas un territorio de libertad (VILLORO, 1997) que marcaba el límite (económico, político y cultural) entre el mundo anglosajón y el hispano, desde el lado mexicano ha sido siempre una zona geopolítica y cultural que, a la vez que denota una amenaza, es también para quienes la cruzan un escaparate para alcanzar nuevos sueños, un lugar "que lucía como el paraíso prometido, y el pueblo como un desolado caserío sin ningún futuro" (PARRA, 1999, p.61). Puede ser un muro infranqueable de separación y segregación y, al mismo tiempo, ser una frontera porosa y flexible.

Por las aguas del río Bravo cruza Makina, la protagonista de la novela de Yuri Herrera, Señales que precederán al fin del mundo (2010). Para cruzar por el continuo urbano que va de Matamoros a Brownsville, o de Nogales (Sonora) a Nogales (Arizona), o de Mexicali a Caléxico, o de Tijuana a San Diego o de Ciudad Juárez a El Paso, el escritor Luis Huberto Crosthwaite nos da instrucciones precisas:

Se requiere un documento que acredite tu nacionalidad y tus intenciones... La paciencia puede ser útil antes de cruzar 
la frontera. Si lo haces en automóvil o caminando, la espera podría ser infinita... Si cruzas en automóvil, que no te extrañe que algunos Aduanas se acerquen con un pero para que husmee tus alrededores... Al enfrentarte a uno de esos guardianes, debes llevar el pasaporte en la mano y la mente en blanco (CROSTHWAITE, 2002, p. 9-11).

Asimismo, por la frontera desértica del norte de México cruzan extravagantes cirqueros para presentar espectáculos fantásticos (MÉNDEZ, 2002) o, tal como lo representa literariamente Eduardo Antonio Parra (1996, 1999), cruzan hombres en busca de un padre que jamás regresó, jóvenes prostitutas(os), mujeres sin hombre, borrachines, periodistas corruptos, campesinos de caseríos y pueblos perdidos, así como quienes se fueron al otro lado, el de la muerte o Estados Unidos, todos ellos desgarrados en la orfandad y la pérdida que supone el ir y venir entre ambos bordes de la frontera, en un movimiento en que no existe ni punto de partida ni de llegada seguro y estable. Desde que en 1996 se colocó un muro fronterizo entre Tijuana y San Ysidro y se reforzaron las medidas de seguridad, el desierto entre Sonora y Arizona se convirtió en la ruta más socorrida, y a la vez más peligrosa, para el cruce ilegal de migrantes. Ello implica caminatas de varios días bajo los intensos rayos del sol o las bajas temperaturas nocturnas. Los migrantes que fracasan en su intento pero que sobreviven a las inclemencias del desierto, son encontrados por los agentes de migración y la patrulla fronteriza deshidratados e inconscientes, con los pies heridos, y en muchos casos abandonados por los "coyotes" que les cobraron por cruzarlos. Muchos mueren de forma anónima (URREA, 2004).

El desierto es, así, un espacio de una abrumadora violencia, en la cual el limite entre la muerte y la vida es casi imperceptible. Pero es asimismo la geografía del olvido. El viento y la arena borran arraigos y huellas. Quien se pierde alli, desaparece. Sus horizontes infinitos esconden ruinas, fantasmas y huellas de quienes por alli cruzaron. El desierto de Atacama, por ejemplo, por sus condiciones particulares de aridez, transparenta la historia y memoria de lo que se esconde; ofrece pistas sobre las voces, experiencias e historias ya silenciadas, como los de las antiguas oficinas salitreras, que ahora son ruinas fantasmales. Por el desierto de Atacama se han perdido seres humanos; sus cuerpos han quedado invisibilizados durante décadas, solidificados en el tiempo, congelada su memoria, vaciada su genealogía. El desierto momifica y preserva; detiene el tiempo, tal como sucedió con el "empampado 
Reflexiones (y una breve travesia literaria) por los desiertos de la frontera norte de Chile y Mexico | 63

Riquelme -tragado por la pampa atacameña- tal como lo reconstruye el escritor chileno Francisco Mouat en su libro del mismo nombre basado en hechos reales. $\mathrm{Al}$ respecto, escribe:

El primero de febrero de 1956, Julio Riquelme Ramírez se subió a un tren en Chillán rumbo al norte, a Iquique. Cuento corto: Julio Riquelme Ramírez jamás llegó a la estación de Iquique... Desde entonces nada se supo de la misteriosa desaparición de Julio Riquelme Ramírez. Nada de nada. Sólo historias de fantasía y después el olvido. Hasta que en enero de 1999 hubo por fin noticias suyas (MOUAT, 2001, p. 17).

Cuarenta años después de su desaparición en medio de la pampa, en medio de la nada, se encontró

un esqueleto humano, blanco-blanco, calcinado por el sol, acostado íntegro sobre el tierra en la misma posición en que lo habían encontrado los presuntos gringos, calzando zapatos, con restos de ropa a su lado con un detalle para mencionar: el zapato derecho sujetaba un sombrero, lo había afirmado durante cuarenta y tres años, para que no se lo llevara el viento (MOUAT, 2001, p. 24).

Evaporado sin sepultura en la aridez del desierto, el viento y el sol del desierto preservaron los huesos de Julio Riquelme a la intemperie, en medio de un lugar de la pampa por donde nadie transitó durante cuarenta y tres años. El libro de Mouart remite, sin duda, a la historia chilena reciente. El desierto de Atacama fue un espacio privilegiado de la violencia estatal durante la dictadura militar encabezada por el General Augusto Pinochet, que lo transformó en cementerio de cientos de cuerpos sin sepultura, víctimas de la "detención-desaparición", la más brutal de las modalidades represivas. La "desaparición” de personas suprime toda huella y es, por consiguiente, el crimen perfecto. Quienes desaparecen son privados del derecho a morir y de que su memoria sea inscrita en una ceremonia de duelo. Carentes de nombre, su desaparición física condensa también la ausencia de rostros o subjetividades. Miles de restos óseos de detenidos desaparecidos, están enterrados en el desierto de Atacama, buscados hasta el dia de hoy por madres y hermanas, tal 


\section{4 | Gilda Waldman Mitnick}

como lo plantea dramáticamente el documental Nostalgia de la luz (dirigido por Patricio Guzmán). Pero el desierto de Atacama también fue el espacio de desaparición de numerosos jóvenes adolescentes de Alto Hospicio, una ciudad marginal surgida en medio del desierto como consecuencia de las migraciones que se dirigieron durante la década de los ochenta a la ciudad de Iquique, una zona franca y desregulada, pero que no pudo incorporar a la gran cantidad de migrantes que llegaban y que a través de la "toma de terrenos" se instalaron en la mitad de la pampa desértica ubicada en las afueras de la ciudad. Empobrecida y degradada, atravesada de punta a punta por redes nacionales y transnacionales de corrupción, narcotráfico y crimen organizado, en Alto Hospicio entre 1994 y 1999 diecisiete adolescentes parecían haber sido devoradas por las arenas del desierto a la salida de la escuela.

Un cuerpo a un costado de la carretera: una silueta, el pelo largo hasta la cintura, una mochila, un jumper, los focos del auto que la iluminan en medio del desierto, de la noche. Un cuerpo a un costado de la carretera, una niña haciendo dedo, la neblina que la empieza a cubrir, las luces del auto iluminándola por unos segundos antes de que desaparezca en medio de la oscuridad. (ZÚÑ̃GA, 2014, p.15)

En medio de la indiferencia de la policía y las autoridades, cuando sus cadáveres -cuerpos desechables, como el de los detenidos desaparecidos, todos igualmente desconocidos y olvidados- fueron encontrados - ¿a partir de la confesión del asesino confeso? estaban irreconocibles, desfigurados, insepultos entre los piques mineros del desierto - especie de túneles desde donde se extraían mineralesdespojados de cualquier inscripción de subjetividad o de identidad familiar o social.

Si en la memoria colectiva el desierto es un lugar de pérdidas, la literatura es un espacio simbólico de memoria. Si Selva Almada aborda en Chicas muertas (ALMADA, 2014) los sórdidos casos jamás resueltos de tres de muchachas asesinadas o desaparecidas en la provincia rural argentina, no sólo como un grito en busca de responsables y de justicia, sino como un gesto de memoria, Diego Zúñiga en Racimo (2015) rescata del olvido la memoria de los huesos de la muchachas asesinadas en Alto Hospicio. También el desierto mexicano guarda huesos de mujeres: los de las muertas asesinadas en Ciudad Juárez, precisamente en la frontera que 
Reflexiones (y una breve travesia literaria) por los desiertos de la frontera norte de Chile y Mexico | 65

separa a México de Estados Unidos (GONZÁLEZ RODRÍGUEZ, 2006), donde cientos de cadáveres de jóvenes sin futuro laboral, avocadas a trabajos informales, parte de una población marginalizada y precarizada, expuestas a la trata de personas y la prostitución, fueron halladas de manera azarosa, como si provinieran de la nada y portando las marcas de terribles violencias sexuales, violación y tortura, apenas ocultos en basurales, descampados, y ciertamente, en una suerte de agujero negro, "entre los matojos amarillos del desierto", como escribe Roberto Bolaño en su novela 2666 (2004), con el eco de los feminicidios de Ciudad de Juárez como fondo. Pero el desierto mexicano también guarda los huesos de los migrantes indocumentados que han decidido cruzar por el desierto de Sonora-Arizona (donde se registra el mayor número de muertes de inmigrantes), inhóspito y casi intransitable, obligados a caminar en un terreno desconocido, sin ropa ni zapatos adecuados, tragados por el calor inclemente, muertos en el anonimato, perseguidos por francotiradores de la policía fronteriza cargados con pistolas de goma, perros amaestrados y sensores, en un espacio que es la cuna de una política racista y xenófoba (URREA, 2004). El desierto de Arizona se ha convertido en una geografía rica en cadáveres que se vuelven polvo, mimetizados con el desierto y que forman parte de sus secretos. El desierto es, así, el guardián de ausencias que no dejan en paz.

No obstante, el desierto es también un espacio de memoria. La pampa atacameña de las oficinas salitreras sobrevive en un imaginario que se resiste a morir: colecciones de fotografias, museos, documentales, teleseries, recuperación de historia oral, etc. (RODRÍGUEZ, MIRANDA y MEGE, 2005). En Pisagua, en 1990, fueron descubiertos en fosas clandestinas los cuerpos momificados de opositores políticos al régimen dictatorial, conservando todavía su última expresión -horror y crispación- en sus esqueléticos rostros. Asimismo, madres, esposas y hermanas siguen buscando, después de tantos años, a sus familiares desaparecidos. $\mathrm{Y}$ en el desierto de Arizona, son frecuentes las peregrinaciones con cruces y flores de papel en memoria de los inmigrantes indocumentados muertos en sus intentos de cruzar la frontera entre México y Estados Unidos.

La tierra calcinada del desierto y su espacio sin vegetación ni habitantes es un paisaje al límite, que no puede reclamarse ni poseerse. Es el hueco en el que la vida opera en ausencia. Es el espacio fascinante que seduce, pero también el territorio peligroso en el que abundan las serpientes y escorpiones. En él se juega siempre entre la vida y la muerte. 


\section{6 | Gilda Waldman Mitnick}

Geografía incierta, puede ser redescubierta una y otra vez. Alli se debe aprender a improvisar, lo que acentúa el desarraigo y, al mismo tiempo, la libertad. En el desierto todo puede ser imaginado y vivido. ¿Cómo podría no ser, entonces, el territorio de la literatura?

\section{BIBLIOGRAFÍA}

ALMADA, Selva. El viento que arrasa. Buenos Aires: Mardulce, 2012. . Ladrilleros. Buenos Aires: Mardulce, 2013. . Chicas muertas. Buenos Aires: Random House Mondadori, 2015.

AMARO, Lorena. Parquecitos de la memoria. En: Revista de la Facultad de Comunicación y Letras, Universidad Diego Portales, vol 27, 2014, pp. 35 42.

ARECO, Macarena. Cartografía de la novela reciente chilena: realismos, experimentalismos, hibridaciones y subgéneros. Santiago: Ceibo, 2015.

BAUMAN, Zygmunt. Modernidad líquida. México: FCE, 2003.

BENGOA, José. La comunidad fragmentada. Santiago: Catalonia, 2009.

BOLAÑO, Roberto. 2666. Barcelona: Anagrama, 2004

CARRERA, Mauricio. Del Panteón al beyond: nociones y tendencias de la nueva narrativa del norte. Casa del Tiempo, (vol) III, Epoca IV, Número 29, 2010, pp. 9-15.

CHAMBERS, Ian. Migración, cultura, identidad. Buenos Aires: Amorrortu, 1994.

CROSTHWAITE, Luis Humberto. Instrucciones para cruzar la frontera. México: Planeta, 2002.

DULAJANOFF, Emma. Cuentos del desierto. México: ediciones Botas, 1959. 
ELIZONDO, Ricardo. Narcedalia Piedrotas. México: Fondo de Cultura Económica, Col Popular, México; 2002.

FORTTES ZALAQUET, Catalina y URZÚA OPAZO, Macarena. Desiertos: paisaje, cuerpo, vida y texto en los límites de lo decible. En: Taller de Letras, (Vol) 55, 2014.

FRANZ, Carlos. El desierto. Santiago: Sudamericana, 2005.

FREIXAS, Meritxell y LABBÉ, Daniel. El andar de los migrantes en nuestro país. En: El Ciudadano, Número 175, marzo 2016.

GARCÍA MÁRQUEZ, Gabriel. La increible y triste historia de la cándida Eréndira y su abuela desalmada. Buenos Aires: Sudamericana, 1976.

GARDEA, Jesús. Reunión de cuentos. México: Fondo de Cultura Económica, 1999.

GIMÉNEZ, Gilberto y Héau Lambert, Catherine. El desierto como territorio, paisaje y referente de identidad. En: Culturales, (vol.) III, núm. 5, enero-junio, 2007, pp. 7-42.

GONZÁLEZ MIRANDA, Sergio. Hombres y mujeres de la Pampa. Tarapacá en el ciclo de expansión del salitre. Santiago: LOM ediciones, 2002.

GONZÁlEZ RODRÍGUEZ, Sergio. Huesos en el desierto. Barcelona: Anagrama, 2006.

HERRERA, Yuri. Señales que precederán al fin del mundo. España: editorial Periférica, 2010.

HOPENHAYN, Martín y SOJO, Ana (orgs.). Sentido de pertenencia en sociedades fragmentadas. América Latina desde una perspectiva global. Argentina: Siglo XXI editores, 2011.

JABÉS, Edmond. Del desierto al libro. Córdoba: Alción, 2001. 
68 | Gilda Waldman Mitnick

JOSELYN-HOLT, Alfredo. 2005. ¿Un proyecto nacional exitoso?. La supuesta excepcionalidad chilena. En: Colom González Francisco (org.). Relatos de nación. La construcción de las identidades nacionales en el mundo hispánico. Madrid/Frankfurt: editorial Iberoamericana Vervuert Verlag, 2005.

KOHUT Karl y MORALES SARAVIA, José (org.). Literatura chilena hoy. La difícil transición. Frankfurt/Main-Madrid, 2002.

LIPOVETZKY, Gilles. La era del vacío. Barcelona: Anagrama, 1986.

LILLO, Baldomero. Sub Sole. Santiago: Imprenta Universitaria, 1907. . Sub Terra. Santiago: Nascimento, 1943.

MANNS, Patricio. Chile: por una narrativa de los espacios abiertos. En: Kohut Karl y MORALES SARAIVA, José (org). Literatura chilena hoy. La dificil transición. Frankfurt/Main-Madrid, 2002.

MÉNDEZ, Miguel. El circo que se perdió en el desierto de Sonora. México: Fondo de Cultura Económica, 2002.

MORALES EBNER, Carla. Voces - 30. Nueva narrativa chilena 2011. Santiago: ebooks Patagonia, 2011.

MOUAT, Francisco. El empampado Riquelme. Santiago: Ediciones B, 2001.

NERUDA, Pablo. Confieso que he vivido. Madrid: Millenium, 1999. .Canto General. Pehuén, 2005.

ONDAATJE, Michael. El paciente inglés. Buenos Aires: Alfaguara, 2007.

OSTRIA GONZÁlEZ, Mauricio. Poéticas del desierto: dos voces. En: Nueva Revista del Pacífico, Universidad de Playa Ancha, Núm. 60, 2014.

PARRA, Antonio Eduardo. Los límites de la noche. México: Era, 1996. . Tierra de nadie. México: Era, 1999. 
Reflexiones (y una breve travesia literaria) por los desiertos de la frontera norte de Chile y Mexico | 69

. Notas sobre la nueva narrativa del norte. En: Estéticas de los confines. org:. Javier Perucho. Morelia: Verdehalago, 2003.

. Norte. Una antología. México: Era / Fondo Editorial de Nuevo León/ Universidad Autónoma de Sinaloa, 2015.

RAJCHENBERG, Enrique y HÉAU-LAMBERT, Catherine. El desierto como representación del territorio septentrional de México. En: Antiteses, vol. 5, núm. 9, enero-julio, 2012, pp. 331-349.

RAMOS BAÑADOS, Rodrigo. Alto Hospicio. Santiago: Quimantú, 2008.

RIVERA, LETELIER, Hernán. La reina Isabel cantaba rancheiras. Chile: Planeta 1998.

Fatamorgana de amor con banda de música. Santiago: Planeta, 1999.

.Los trenes se van al purgatorio. Santiago: Planeta, 2000.

.Santa Maria de las flores negras. Buenos Aires: Seix Barral, 2002.

.Canción para caminar sobre las aguas. Santiago: Planeta 2004.

.El arte de la resurrección. México: Alfaguara, 2010.

RODRÍGUEZ, Juan Carlos et al. Memoria y conciencia utópica: una arqueología desde la ausencia. Ponencia presentada al Cuarto Congreso Chileno de Antropología, 10-23 de noviembre, Campus Juan Gómez Millas, Universidad de Chile, 2001.

RODRÍGUEZ, Juan Carlos, MIRANDA, Pablo, MEGE, Pedro. Réquiem para María Elena: Notas sobre el imaginario de los últimos pampinos. En: Estudios atacameños, Núm. 30, 2005.

RONCINO, Hernán. La descomposición. Buenos Aires: Eterna Cadencia, 2007.

. Glaxo. Buenos Aires: Eterna Cadencia, 2009. 
.Lumbre. Buenos Aires: Eterna Cadencia, 2013.

RUBIN, Ramón. Cuando el Táguaro agoniza. México: Editorial Azteca, 1960.

SCARPA, Roque Esteban. (selección de prosa y editor). Gabriela anda por el mundo. Santiago: editorial Andrés Bello, 1978.

SALINAS, Juan Luis. Mujeres en la frontera. En: El Mercurio, 27 noviembre 2015.

TEITELBOIM, Volodia. Hijos del salitre. Santiago: Austral, 1952.

.La semilla en la arena. Santiago, LOM ediciones, 2002.

SABELLA, Andrés. Norte Grande. Santiago: edit. Orbe, 1966.

URREA, Luis Alberto. The Devil's Highway. New York/Boston/London, Back Bay Books, 2004.

VALENZUELA, José Manuel (org.). Por las fronteras del norte. Una aproximación cultural a la frontera México-Estados Unidos. México: Fondo de Cultura Económica, 2003.

VIDAL, Hernán. Chile: la poética de la tortura política. Santiago: Mosquito editores, 2000.

VILLORO, Juan. La frontera de los ilegales. En: Domenella Ana Rosa et al (org.). Medio siglo de literatura latinoamericana. 1945-1995. México: Universidad Autónoma Metropolitana, 1997.

VIÑAS, David. Indios, ejército y frontera. Buenos Aires: Siglo XXI, 1983.

WIESEL, Elie. ¿Quién le teme al lobo feroz? En: "Los emigrantes", Suplemento Mundial de La Jornada, 23 de junio 1993.

ZÚÑIGA, Diego. Camanchaca. Santiago: Random House Mondadori, 2012. 
Reflexiones (y una breve travesia literaria) por los desiertos de la frontera norte de Chile y Mexico | 71

Racimo. Santiago: Random House Mondadori, 2014.

Recebido em: 26/08/2016

Aceito em: 16/09/2016 
72 | Gilda Waldman Mitnick

Caderno de Letras, n ${ }^{\circ}$ 27, Jul-Dez - 2016 - ISSN 0102-9576 